\title{
FGFR2 mutations and associated clinical observations in two Chinese patients with Crouzon syndrome
}

\author{
YING LIN $^{1 *}$, HONGBIN GAO ${ }^{2,3^{*}}$, SIMING AI $^{*}$, JACOB V.P.ESWARAKUMAR ${ }^{4 *}$, YI ZHU $^{1,5}$, \\ CHUAN CHEN $^{1,5}$, TAO LI ${ }^{1}$, BINGQIAN LIU ${ }^{1}$, HONGYE JIANG ${ }^{6}$, YUHUA LIU ${ }^{1}$, YONGHAO LI ${ }^{1}$, \\ QINGXIU WU ${ }^{1}$, HAICHUN LI ${ }^{1}$, XIAOLING LIANG ${ }^{1}$, CHENJIN JIN $^{1}$, XINHUA HUANG $^{1 *}$ and LIN LU ${ }^{1 *}$ \\ ${ }^{1}$ State Key Laboratory of Ophthalmology, Zhongshan Ophthalmic Center, Sun Yat-Sen University, \\ Guangzhou, Guangdong 510060; ${ }^{2}$ Department of Toxicology, School of Public Health and Tropical Medicine, Southern \\ Medical University, Guangzhou, Guangdong 510515; ${ }^{3}$ Guangdong Laboratory Animals Monitoring Institute, Key Provincial \\ Laboratory of Guangdong Laboratory Animals, Guangzhou, Guangdong 510663, P.R. China; ${ }^{4}$ Department of Orthopaedics \\ and Rehabilitation, Yale University School of Medicine, New Haven, CT 06520; ${ }^{5}$ Department of Molecular and Cellular \\ Pharmacology, University of Miami Miller School of Medicine, Miami, FL 33136, USA; ${ }^{6}$ Department of Obstetrics \\ and Gynecology, The First Affiliated Hospital, Sun Yat-Sen University, Guangzhou, Guangdong 510000, P.R. China
}

Received March 16, 2017; Accepted July 11, 2017

DOI: $10.3892 / \mathrm{mmr} .2017 .7397$

\begin{abstract}
The aim of the present study was to identify mutations in the fibroblast growth factor receptor 2 (FGFR2) gene in patients with Crouzon syndrome and characterize the associated clinical features. A total of two Chinese patients diagnosed with Crouzon syndrome underwent complete examinations, including best-corrected visual acuity, slit-lamp, examination, fundus examination, optical coherence tomography and computed tomography of the skull. Genomic DNA was extracted from peripheral blood samples collected from the patients, as well as their family members and 200 unrelated control subjects from the same population. Exons 8 and 10 in the FGFR2 gene were amplified by polymerase chain reaction and directly sequenced. Patient \#1 had a heterozygous missense mutation (c.1025G >A, p.C342Y) in exon 10 of FGFR2. Patient \#2 had a heterozygous mutation (c.1084+1 $\mathrm{G}>\mathrm{T}$; IVS10+1G $>\mathrm{T}$ ) in intron 10 . The mutations were not present in any of the unaffected family members or unrelated control subjects. These findings expand the mutation spectrum of FGFR2, and are valuable for genetic counseling in addition to prenatal diagnosis in patients with Crouzon syndrome.
\end{abstract}

Correspondence to: Professor Xinhua Huang or Professor Lin Lu, State Key Laboratory of Ophthalmology, Zhongshan Ophthalmic Center, Sun Yat-Sen University, South Road 54, Yuexiu, Guangzhou, Guangdong 510060, P.R. China

E-mail: 1476557150@qq.com

E-mail: drlulin@126.com

${ }^{*}$ Contributed equally

Key words: Crouzon syndrome, FGFR2 gene, mutation

\section{Introduction}

Craniosynostosis is characterized by premature fusion of one or more cranial sutures, resulting in an abnormal growth pattern of the skull (1). Craniosynostosis can be clinically manifested as Crouzon syndrome, Jackson-Weiss syndrome, or Pfeiffer syndrome. Crouzon syndrome, first reported by Louis Edouard Octave (2-5) in 1912, is recognized as one of the most common craniosynostosis syndromes (6). The prevalence of Crouzon syndrome is between $1 / 60,000$ to $1 / 1,000$ live birth, depending on race, region, and ethnicity (7-9). Crouzon syndrome is typically characterized by craniosynostosis, exorbitism, hypertelorism, midface hypoplasia, hooked nose, thin vermilion of the upper lip, and mandibular prognathism $(10,11)$. Unlike Pfeiffer syndrome that can present hand abnormalities, such as wide and deviated thumbs, or Jackson-Weiss syndrome that can present broad great toes with medial deviation and tarsal-metatarsal coalescence, Crouzon syndrome usually does not present limb abnormalities $(1,9)$. Most patients with Crouzon syndrome present altered ocular appearance such as ocular proptosis, and initially seek medical care from neurosurgeons or ophthalmologists, rather than orthopedists $(8,12,13)$. Since Crouzon syndrome is a relatively rare syndrome, and is usually not easy to diagnose, molecular diagnosis will provide useful information for the disease diagnosis and genetic counseling.

Craniosynostosis is generally associated with abnormal function of fibroblast growth factor receptors (FGFRs) $(14,15)$. To date, more than 50 distinct mutations in the FGFR2 gene have been linked to Crouzon syndrome. Approximately $95 \%$ of patients have a mutation in either 8 (IIIa) or exon 10 (IIIc), which encode the extracellular immunoglobulin-like III (IgIII) domain of the receptor $(14,16)$. Growth factors, such as FGF and TGF, play pivotal roles for controlling cell growth and differentiation (17-23). Mutations in FGFR2 can lead to increased ligand affinity and altered ligand specificity, disrupting the differentiation of mesenchymal stem cells, and 
therefore causing developmental defects $(24,25)$. Although Crouzon syndrome is often inherited as an autosomal dominant trait, de novo mutations at FGFR2 can also result in sporadic cases $(3,5,26)$. Here, we report the results of a mutational analysis of two sporadic patients with Crouzon syndrome from two unrelated Chinese families.

\section{Materials and methods}

Patient recruitment and clinical evaluations. All experimental protocols and methods which were carried out in accordance with the guidelines were approved by the Ethics Committee of Zhongshan Ophthalmic Center. Informed consents were obtained from all participating subjects in accordance with the Declaration of Helsinki. The following series of ophthalmic tests were performed in patients and their family members. Visual acuity was examined using the Early Treatment Diabetic Retinopathy Study (EDTRS) chart (Precision Vision, LaSalle, IL, USA). Anterior segment photographs were captured by a BX 900 slit lamp (Haag-Streit AG, Köniz, Switzerland). Anterior segment measurements were obtained by a Pentacam HR version 70700 (OCULUS Optikgeräte $\mathrm{GmbH}$, Wetzlar, Germany). Optical coherence tomography (OCT) was carried out by Cirrus HD-OCT (Carl Zeiss Meditec, Dublin, CA, USA). Computed tomography (CT) and physical examinations, including blood examination, urinalysis, electrocardiogram, chest X-ray, blood biochemistry, blood lipid, and blood coagulation tests, were conducted to exclude systemic diseases.

Sample collection and mutational screening. Genomic DNA samples were extracted from peripheral blood leucocytes of the patients and their relatives with the Qiagen kit (Qiagen Inc., Chatsworth, CA, USA) according to the manufacturer's instructions. DNA concentration and purity were measured by NanoDrop ${ }^{\mathrm{TM}}$ ND-1000 spectrophotometer (Thermo Fisher Scientific Inc., Wilmington, DE, USA). In addition, DNA samples collected from 200 subjects from the same population without diagnostic features of Crouzon syndrome were used as controls. Exons 8 and 10 in the FGFR2 gene were amplified using polymerase chain reaction (PCR) as described previously $(24,25,27)$. Primers were obtained from the Beijing Genomics Institute (Guangzhou, China). The sequences of the primers are listed in Table I. All reagents used for the PCR reactions were purchased from Takara Bio Inc. (Tokyo, Japan). The amplification included a single 5-min step at $94^{\circ} \mathrm{C}$; followed by 40 cycles of $94^{\circ} \mathrm{C}$ for $45 \mathrm{sec}, 61^{\circ} \mathrm{C}$ for $45 \mathrm{sec}$, and $72^{\circ} \mathrm{C}$ for $45 \mathrm{sec}$; and finally a 10 -min step at $72^{\circ} \mathrm{C}$. The PCR products were sequenced in both directions using an ABI3730 Automated Sequencer (PE Biosystems, Foster City, CA, USA). The sequencing results were analyzed using SeqMan (version 2.3; Technelysium Pty, Ltd., Brisbane, QLD, Australia), and compared against reference sequences obtained from the National Center for Biotechnology Information (NCBI) database (accession no. NC_000010) (28).

\section{Results}

Clinical presentations. We diagnosed two patients of two unrelated families from the southern region of China. Systemic diseases were excluded upon examination.
Patient \#1 was a two-year-old girl and was the only child of two healthy parents (Fig. 1). She was referred by her local pediatrician at two months of age due to concerns about an elongated head shape and the possible diagnosis of sagittal synostosis. Until this point, the patient's development was otherwise unremarkable, with normal feeding and steady weight gain after birth. Examination of this patient revealed shallow orbits and ocular proptosis, accompanied by midface hypoplasia, craniosynostosis, a curved beak-like nose (Fig. 1A), and clinically normal hands and feet. An approximately $2 \mathrm{~mm}$ gap was observed when she attempted to close her eyelids (Fig. 1B). The patient presented with exotropia in both eyes, but the corneas were transparent with normal size. Also, the lenses were transparent and normally positioned (Fig. 1C and D). Fundus examination showed normal retinas (Fig. 1E and F). Because of the patient was young, we were unable to measure visual acuity, but the child had normal visual tracking and the results of the optometry were +3.0 D (OD) and +3.25 D (OS). CT scan revealed shallow orbits and exotropia in both eyes (Fig. 1G). Both parents had normal visual acuity and unremarkable eye examinations, and all family members had no known history of learning difficulties or genetic problems.

Patient \#2 was a 21-year-old woman and was also the only child of two healthy parents (Fig. 2). She presented with midface hypoplasia and craniosynostosis (Fig. 2A). She had normal visual acuity. Her hands and feet had normal flexibility. Radiography showed no obvious carpal fusion (Fig. 2B and C). No abnormalities were detected in the cornea or lens (Fig. 2D and E). CT scan revealed shallow orbits (Fig. 2F). OCT revealed normal retina in both eyes (Fig. $2 \mathrm{G}$ and $\mathrm{H}$ ). In general, the clinical manifestations of this patient were less severe than patient \#1.

Mutational screening. Patient \#1 carried a heterozygous missense mutation (c.1025G $>$ A; p.C342Y) in exon 10 of the FGFR2 gene (Fig. 3A). Patient \#2 carried a heterozygous mutation (IVS10+1G>T; c.1084+1 G>T) in intron 10 of the FGFR2 gene (Fig. 3B). This mutation is located at a splicing site. Both mutations were not presented in any of the unaffected family members or unrelated controls, therefore are considered de novo mutations.

Clinical manifestations and mutational screening results of the two patients in this study are summarized in Table II.

\section{Discussion}

Crouzon syndrome is a common autosomal dominant form of craniofacial complexes, characterized by premature craniosynostosis, orbital proptosis, and midface hypoplasia (7). Both patients we reported here do not present limb malformations, which differentiates Crouzon syndrome from other types of craniosynostosis $(1,9)$.

In patient \#1, the c. $1025 \mathrm{G}>\mathrm{A}$ mutation causes a cysteine-to-tyrosine substitution at amino acid 342 in FGFR2. The loss of this cysteine residue is one of the most frequent mutations in Crouzon syndrome patients and has been reported in French, British, and German populations $(5,6,29-32)$. Therefore, the amino acid C342 in FGFR2 is considered as a mutation 'hotspot'. Several identified mutations at this position are C342R (c.1024T>C), C342Y 
Table I. Summary of the primers and product length used for the amplification of the exons of FGFR 2.

\begin{tabular}{lllcc}
\hline Exon & Forward (5'-3') & Reverse $\left(5^{\prime}-3^{\prime}\right)$ & $\begin{array}{c}\text { Product } \\
\text { size (bp) }\end{array}$ & $\begin{array}{c}\text { Annealing } \\
\text { temperature }\left({ }^{\circ} \mathrm{C}\right)\end{array}$ \\
\hline FGFR2-8 $($ IIIa $)$ & GGTCTCTCATTCTCCCATCCC & CCAACAGGAAATCAAAGAACC & 325 & 61 \\
FGFR2-10 $($ IIIc $)$ & CCTCCACAATCATTCCTGTGTC & ATAGCAGTCAACCAAGAAAAGGG & 257 & 61 \\
\hline
\end{tabular}
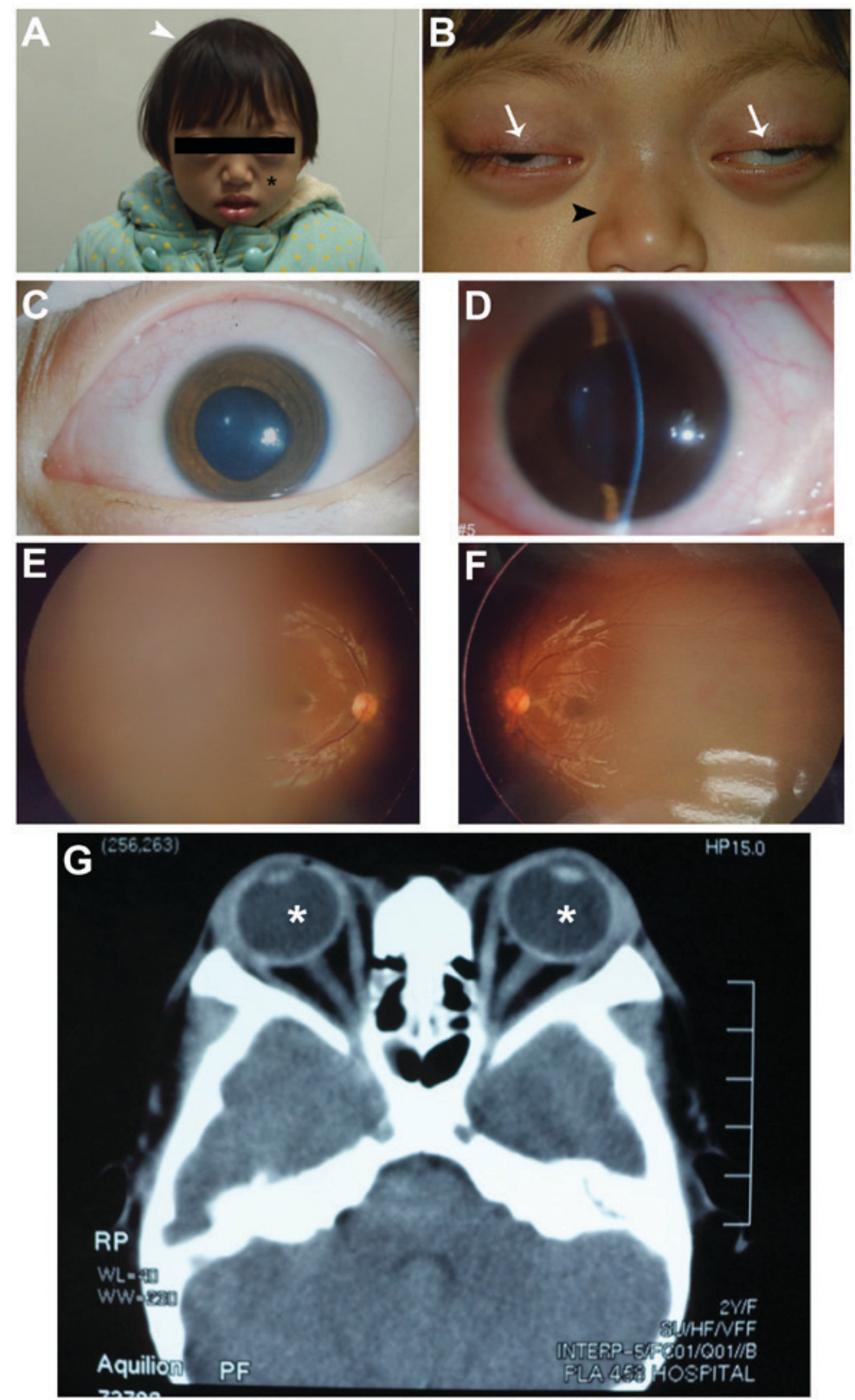

Figure 1. Clinical manifestations of patient \#1. (A and B) The patient presented with ocular proptosis (white arrows), extropia, midface hypoplasia (black asterisk), craniosynostosis (white arrowhead), and a curved, beak-like nose (black arrowhead). An approximately $2 \mathrm{~mm}$ gap was observed when she attempted to close her eyelids. (C and D) The corneas of both eyes were transparent with normal size, and the lenses are clear and normally postioned. (E and F) Fundus examination showed normal retina in both eyes. (G) A CT scan reveals shallow orbits and exotropia in both eyes (white asterisks).

(c.1025G $>$ A), C342S (c.1025G>C), C342F (c.1025G >T), and $\mathrm{C} 342 \mathrm{~W}(\mathrm{c} .1026 \mathrm{C}>\mathrm{G})(30,32,33)$. Mutations at $\mathrm{C} 342$ can cause Crouzon syndrome as well as Pfeiffer syndrome (34). Studies have shown that $\mathrm{C} 342$ is part of the disulfide bridge that stabilizes the IgIII loop in all FGFR proteins and is the most conserved extracellular amino acid in the $\mathrm{Ig}$ superfamily. The loss of C342 leaves an unbridged C278, which may cause the ligand-independent dimerization of receptor molecules, leading to constitutive receptor activation $(35,36)$. 
Table II. Summary of clinical manifestations and mutational screening results of the two patients.

\begin{tabular}{|c|c|c|c|c|c|c|c|c|}
\hline \multirow[b]{2}{*}{ Patient (\#) } & \multirow[b]{2}{*}{ Gender } & \multirow[b]{2}{*}{ Age } & \multicolumn{5}{|c|}{ Clinical manifestations } & \multirow[b]{2}{*}{ Mutation } \\
\hline & & & Facial characteristics & Limbs & Lens/cornea & Fundus & CT scan & \\
\hline 1 & Female & 2 & $\begin{array}{l}\text { Midface hypoplasia, } \\
\text { craniosynostosis, } \\
\text { curved beak-like } \\
\text { nose, lagophthalmus }\end{array}$ & Normal & Normal & Normal & $\begin{array}{l}\text { Shallow } \\
\text { orbits, } \\
\text { proptosis, } \\
\text { exotropia }\end{array}$ & c. $1025 \mathrm{G}>\mathrm{A}$ \\
\hline 2 & Female & 21 & $\begin{array}{l}\text { Midface } \\
\text { hypoplasia, } \\
\text { craniosynostosis }\end{array}$ & Normal & Normal & Normal & Shallow orbits & $\begin{array}{l}\text { c. } 1084+1 \\
\mathrm{G}>\mathrm{T}, \mathrm{IVS} 10 \\
\quad+1 \mathrm{G}>\mathrm{T} ;\end{array}$ \\
\hline
\end{tabular}
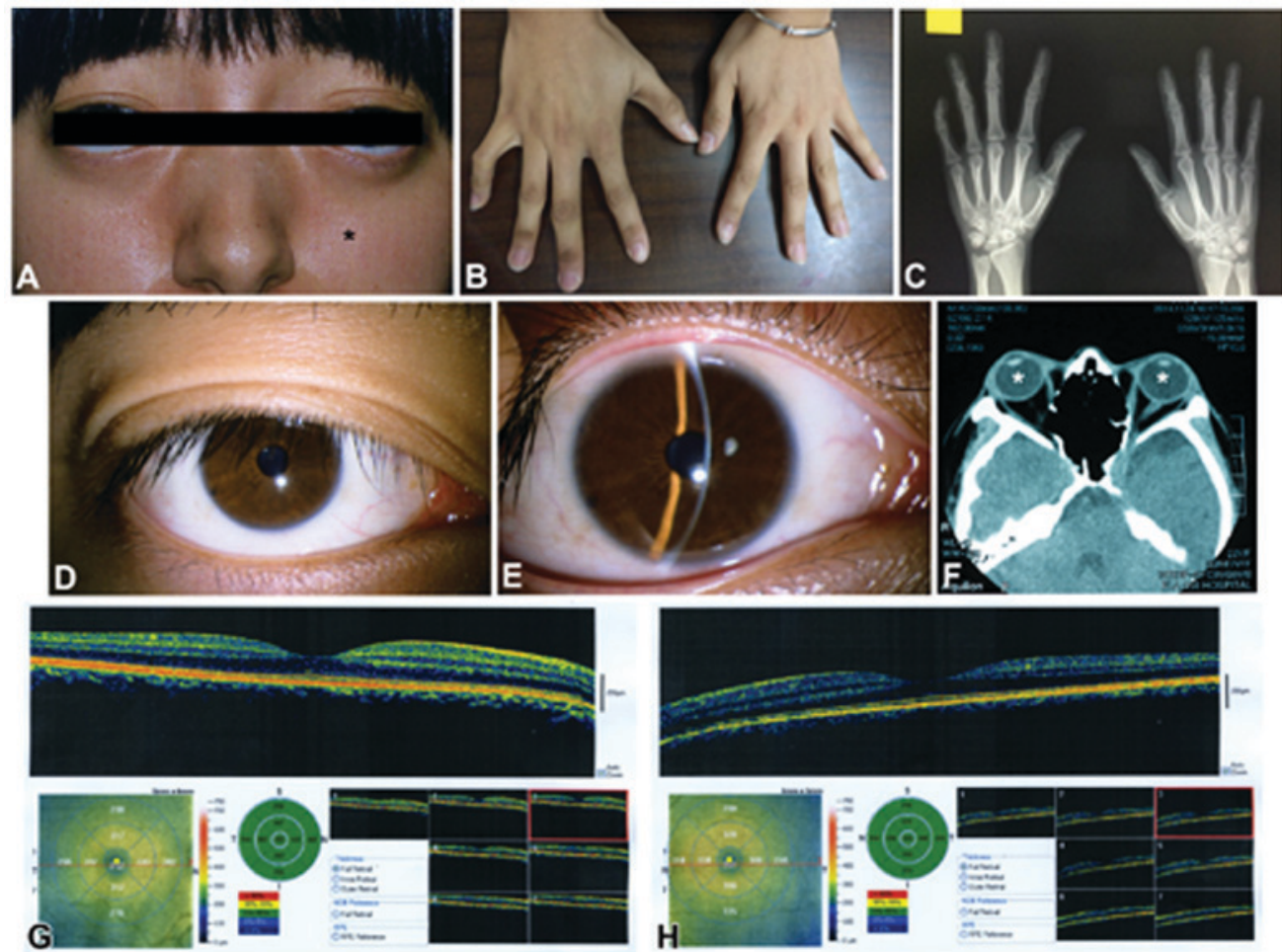

Figure 2. Clinical manifestations of patient \#2. (A) The patient presented with midface hypoplasia (black asterisk). (B) Clinically normal hands. (C) Radiography revealed no obvious carpal fusions in this patient. (D and E) The cornea and lenses were normal. (F) CT scan revealed shallow orbits (white asterisks). ( $\mathrm{G}$ and $\mathrm{H}$ ) OCT examination revealed normal retina in both eyes.

A

Normal

Patient \#1
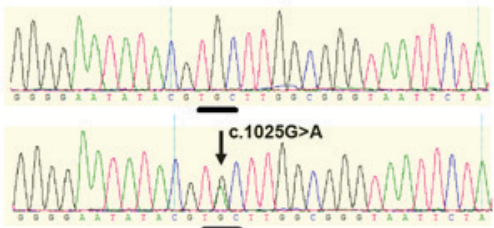

B

Normal

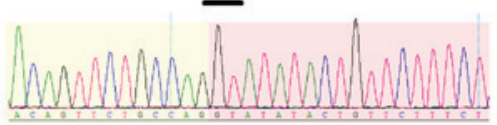

Patient \#2

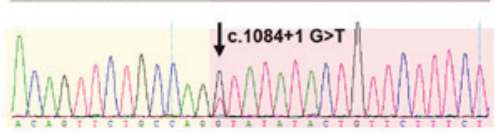

Figure 3. Mutational screening results of the patients. (A) A heterozygous missense mutation (c.1025G>A; p.C342Y) in exon 10 of the FGFR2 gene was identified in patient \#1. (B) A heterozygous mutation (IVS10+1 G>T; c.1084+1 G>T) in intron 10 of the FGFR2 gene was identified in patient \#2. Yellow boxes denote exon regions. Pink boxes denote intron regions.
The fidelity of the splice site sequence, particularly the first two nucleotides in the donor site, is essential for accurate splicing. The presence of a guanine base at the +1 position at the intron-exon boundary of FGFR2 gene is essential for splice site recognition. In patient \#2, the splicing site mutation (c.1084+1 G>T) can cause alternative splicing, disrupt the third immunoglobulin-like domain of FGF2, and generate pathogenic protein isoforms. However, compared to the cysteine mutation in Patient \#1, mutations affecting FGFR2 pre-mRNA splicing usually cause relatively mild clinical manifestations (37-39). Interestingly, a similar mutation in the FGFR2 gene at the same position (c.1084+1 G>A) can cause mild bicoronal synostosis (38).

Craniosynostosis may be complicated with other ophthalmic anomalies. For example, some craniosynostosis patients with FGFR2 mutation can also present with Peters anomaly (a rare 
form of anterior segment dysgenesis), optic nerve hypoplasia, scleralization of the cornea, and corectopia (13). In this study, patient \#1 also had strabismus, which expands the list of clinical manifestations associated with Crouzon syndrome.

In summary, we identified two distinct mutations in the FGFR2 gene in two Chinese patients with Crouzon syndrome from unrelated families. These findings expand the mutational spectrum of $F G F R 2$, and provide valuable information for genetic counseling and prenatal diagnosis in families with Crouzon syndrome. Although our understanding of the function of FGFR is still limited, the discovery of these mutant variants provides an opportunity and rationale for in-depth mechanistic studies, and may help to reveal critical pathophysiology underlying related skull development disorders in general.

\section{Acknowledgements}

This study was supported by the National Natural Science Foundation of China (grant nos. 81500709, 81570862, 81670872), the State Scholarship Fund from the China Scholarship Council, the Medical Scientific Research Foundation of Guangdong Province (grant no. A2016460) and the National Institute of Dental and Craniofacial Research (grant no. DE020823).

\section{References}

1. Wilkie AO: Craniosynostosis: Genes and mechanisms. Hum Mol Genet 6: 1647-1656, 1997.

2. Mitulla B, Hinkel GK and Lorenz P: Crouzon syndrome (Mc K 12350). Kinderarztl Prax 59: 278-280, 1991 (In German).

3. Kaur H, Singh Waraich H and Sharma CM: Crouzon syndrome: A case report and review of literature. Indian J Otolaryngol Head Neck Surg 58: 381-382, 2006.

4. Khandelwal R, Agrawal P and Majumdar MR: Crouzon syndrome. BMJ Case Rep 2012: 2012.

5. Reardon W, Winter RM, Rutland P, Pulleyn LJ, Jones BM and Malcolm S: Mutations in the fibroblast growth factor receptor 2 gene cause Crouzon syndrome. Nat Genet 8: 98-103, 1994.

6. Liu J, Kwon TG, Nam HK and Hatch NE: Craniosynostosis-associated Fgfr2(C342Y) mutant bone marrow stromal cells exhibit cell autonomous abnormalities in osteoblast differentiation and bone formation. Biomed Res Int 2013: 292506, 2013.

7. Bowling EL and Burstein FD: Crouzon syndrome. Optometry 77: 217-222, 2006

8. Giordano BP, Tuli SS, Ryan SF, Stern M and Tuli SY: Crouzon syndrome: Visual diagnosis. J Pediatr Health Care 30: 270-273, 2016.

9. Barik M, Bajpai M, Malhotra A, Samantaray JC, Dwivedi S and Das S: Novel mutation detection of fibroblast growth factor receptor 1 (FGFR1) gene, FGFR2IIIa, FGFR2IIIb, FGFR2IIIc, FGFR3, FGFR4 gene for craniosynostosis: A prospective study in Asian Indian patient. J Pediatr Neurosci 10 207-213, 2015.

10. Kreiborg S: Crouzon syndrome: A clinical and roentgencephalometric study. Scand J Plast Reconstr Surg Suppl 18: 1-198, 1981.

11. Shotelersuk V, Mahatumarat C, Ittiwut C, Rojvachiranonda N, Srivuthana S, Wacharasindhu S and Tongkobpetch S: FGFR2 mutations among Thai children with Crouzon and Apert syndromes. J Craniofac Surg 14: 101-107, 2003.

12. Sastre-Ibáñez M, Garcia-Asorey A, Santos-Bueso E, Lerma-Gallardo JL, Garcia-Sáenz S and Garcia-Feijoo J: Crouzon syndrome: Ophthalmologic complications in an untreated adult patient. J Fr Ophtalmol 38: e177-e178, 2015.

13. Okajima K, Robinson LK, Hart MA, Abuelo DN, Cowan LS, Hasegawa T, Maumenee IH and Jabs EW: Ocular anterior chamber dysgenesis in craniosynostosis syndromes with a fibroblast growth factor receptor 2 mutation. Am J Med Genet 85: 160-170, 1999.
14. Guo L, Lai YN and Li LX: FGFR2 gene mutation in a family with Crouzon syndrome and a sporadic Crouzon syndrome patient. Zhonghua Yi Xue Yi Chuan Xue Za Zhi 25: 218-220, 2008 (In Chinese)

15. Cunningham ML, Seto ML, Ratisoontorn C, Heike CL and Hing AV: Syndromic craniosynostosis: From history to hydrogen bonds. Orthod Craniofac Res 10: 67-81, 2007.

16. Gorry MC, Preston RA, White GJ, Zhang Y, Singhal VK, Losken HW, Parker MG, Nwokoro NA, Post JC and Ehrlich GD: Crouzon syndrome: Mutations in two spliceoforms of FGFR2 and a common point mutation shared with Jackson-Weiss syndrome. Hum Mol Genet 4: 1387-1390, 1995.

17. Kitisin K, Saha T, Blake T, Golestaneh N, Deng M, Kim C, Tang Y, Shetty K, Mishra B and Mishra L: Tgf-beta signaling in development. Sci STKE: cm1, 2007.

18. Tan X, Zhu Y, Chen C, Chen X, Qin Y, Qu B, Luo L, Lin H, Wu M, Chen W and Liu Y: Sprouty2 suppresses epithelial-mesenchymal transition of human lens epithelial cells through blockade of Smad2 and ERK1/2 pathways. PLoS One 11: e0159275, 2016

19. Turner N and Grose R: Fibroblast growth factor signalling: From development to cancer. Nat Rev Cancer 10: 116-129, 2010.

20. Coutts JC and Gallagher JT: Receptors for fibroblast growth factors. Immunol Cell Biol 73: 584-589, 1995.

21. Zhang Y, Morgan R, Chen C, Cai Y, Clark E, Khan WN, Shin SU, Cho HM, Al Bayati A, Pimentel A and Rosenblatt JD: Mammary-tumor-educated B cells acquire LAP/TGF- $\beta$ and PD-L1 expression and suppress anti-tumor immune responses. Int Immunol 28: 423-433, 2016.

22. Chen C, Zhu Y, Lin Y, Liu Z, Wu M, Li D and Cheng B: Suppression of retinal pigment epithelial cell proliferation, migration and epithelial-mesenchymal transition by proteasome inhibition, a potential defense against proliferative vitreoretinopathy. Investigative Ophthalmol Visual Sci 54: 6254, 2013.

23. Zhu Y, Chen C, Lin Y, Liu Y and Wu M; Cataract Lab: Downregulation of syndecan-4 by RNA interference inhibits adhesion and bFGF-induced proliferation of lens epithelial cells. Invest Ophthalmol Vis Sci 54: 479, 2013.

24. Lin Y, Ai S, Chen C, Liu X, Luo L, Ye S, Liang X, Zhu Y, Yang H and Liu Y: Ala344Pro mutation in the FGFR2 gene and related clinical findings in one Chinese family with Crouzon syndrome. Mol Vis 18: 1278-1282, 2012.

25. Lin Y, Liang X, Ai S, Chen C, Liu X, Luo L, Ye S, Li B, Liu Y and Yang H: FGFR2 molecular analysis and related clinical findings in one Chinese family with Crouzon syndrome. Mol Vis 18: 449-454, 2012

26. Matsumoto K, Urano Y, Kubo Y, Nakanishi H and Arase S: Mutation of the fibroblast growth factor receptor 2 gene in Japanese patients with Apert syndrome. Plast Reconstr Surg 101: 307-311, 1998.

27. Lin Y, Liu X, Yu S, Luo L, Liang X, Wang Z, Chen C, Zhu Y, Ye S, Yan H and Liu Y: PAX6 analysis of two sporadic patients from southern China with classic aniridia. Mol Vis 18: 2190-2194, 2012.

28. Li T, Lin Y, Gao H, Chen C, Zhu Y, Liu B, Lian Y, Li Y, Zhou W, Jiang $\mathrm{H}$ and $\mathrm{Li} \mathrm{H}$ : Two heterozygous mutations identified in one Chinese patient with bilateral macular coloboma. Mol Med Rep: Jun 29, 2017 (Epub ahead of print).

29. Bagheri-Fam S, Ono M, Li L, Zhao L, Ryan J, Lai R, Katsura Y, Rossello FJ, Koopman P, Scherer G, et al: FGFR2 mutation in 46,XY sex reversal with craniosynostosis. Hum Mol Genet 24: 6699-6710, 2015.

30. Ke R, Yang X, Tianyi C, Ge M, Lei J and Mu X: The C342R mutation in FGFR2 causes Crouzon syndrome with elbow deformity. J Craniofac Surg 26: 584-586, 2015.

31. Sun LL, Li M, Suo F, Liu XM, Shen EZ, Yang B, Dong MQ, He WZ and Du LL: Global analysis of fission yeast mating genes reveals new autophagy factors. PLoS Genet 9: e1003715, 2013.

32. Mangasarian K, Li Y, Mansukhani A and Basilico C: Mutation associated with Crouzon syndrome causes ligand-independent dimerization and activation of FGF receptor-2. J Cell Physiol 172: 117-125, 1997.

33. Pandey RK, Bajpai M, Ali A, Gayan S and Singh A: Mutational identification of fibroblast growth factor receptor 1 and fibroblast growth factor receptor 2 genes in craniosynostosis in Indian population. Indian J Hum Genet 19: 449-453, 2013.

34. Glaser RL, Jiang W, Boyadjiev SA, Tran AK, Zachary AA, Van Maldergem L, Johnson D, Walsh S, Oldridge M, Wall SA, et al: Paternal origin of FGFR2 mutations in sporadic cases of Crouzon syndrome and Pfeiffer syndrome. Am J Hum Genet 66: 768-777, 2000. 
35. Kress W, Collmann H, Büsse M, Halliger-Keller B and Mueller CR: Clustering of FGFR2 gene mutations inpatients with Pfeiffer and Crouzon syndromes (FGFR2-associated craniosynostoses). Cytogenet Cell Genet 91: 134-137, 2000.

36. Robertson SC, Meyer AN, Hart KC, Galvin BD, Webster MK and Donoghue DJ: Activating mutations in the extracellular domain of the fibroblast growth factor receptor 2 function by disruption of the disulfide bond in the third immunoglobulin-like domain. Proc Natl Acad Sci USA 95: 4567-4572, 1998.

37. Cohen MM and MacLean RE: Craniosynostosis: Diagnosis, Evaluation and Management. 2nd edition. Oxford University Press, New York, NY, pp454, 2000.
38. Traynis I, Bernstein JA, Gardner P and Schrijver I: Analysis of the alternative splicing of an FGFR2 transcript due to a novel 5'splice site mutation $(1084+1 \mathrm{G}>\mathrm{A})$ : Case report. Cleft Palate Craniofac J 49: 104-108, 2012.

39. Burgess K and Price J: Whey to Go Whey Protein Concentrate: A New Zealand Success Story. MacGibbon J (ed). Ngaio Press, Martinborough, New Zealand, pp264, 2014. 